\title{
Recorded quality of primary care for osteoarthritis: an observational study
}

\author{
Joanne Broadbent, Susan Maisey, Richard Holland and Nicholas Steel
}

\author{
ABSTRACT

\section{Background} \\ Osteoarthritis is the most common chronic disease in \\ the UK, with greater prevalence in women, older \\ people, and those with poorer socioeconomic status. \\ Effective treatments are available, yet little is known \\ about the quality of primary care for this disabling \\ condition. \\ Aim \\ To measure the recorded quality of primary care for \\ osteoarthritis, and assess variations by patient and/or \\ practice characteristics.

\section{Design of study} \\ Retrospective observational study.

\section{Setting} \\ Eighteen general practices in England.

\section{Method} \\ Records of $320 / 393$ randomly selected patients with \\ osteoarthritis (response rate $81 \%$ ) were reviewed. \\ High-quality health care was specified by nine quality \\ indicators. Logistic regression modelling assessed \\ variations in quality by age, sex, deprivation, severity, \\ time since diagnosis, and practice size.

\section{Results} \\ There was substantial variation in the recorded \\ achievement of individual indicators (range $5 \%$ to \\ $90 \%$ ). The percentage of eligible patients whose \\ records show that they received care in the form of \\ information provision ranged from $17 \%$ to $30 \%$. For \\ regular assessment indicators the range was $27 \%$ to \\ $43 \%$, and for treatment indicators the range was $5 \%$ to \\ $90 \%$. Recorded achievement of quality indicators was \\ higher in those with more severe osteoarthritis (odds \\ ratio $[\mathrm{OR}] 1.38,95 \% \mathrm{Cl}=1.13$ to 1.69 ) and in older \\ patients (OR 1.14, 95\% Cl=1.02 to 1.28). There were \\ no significant variations by deprivation score.

\section{Conclusion} \\ This study has demonstrated the feasibility of using \\ existing robust quality indicators to measure the quality \\ of primary care for osteoarthritis, and has found \\ considerable scope for improvement in the recording \\ of high-quality care. The lack of variation between \\ practices suggests that system-level initiatives may be \\ needed to achieve improvement. One challenge will be \\ to improve care for all, without losing the equitable \\ distribution of care identified.

\section{Keywords} \\ osteoarthritis; primary health care; quality of health \\ care; quality indicators.
}

\section{INTRODUCTION}

Osteoarthritis causes substantial morbidity in developed countries. In the UK it is the most prevalent chronic disease among adults aged 65 years and over, affecting $32 \%$ of men and $47 \%$ of women. ${ }^{1}$ It is also the most common cause of disability. ${ }^{2}$ Osteoarthritis is an age-related condition, ${ }^{3}$ and there is a greater level of need among women and those from more deprived backgrounds. ${ }^{4}$ Those in poorer socioeconomic groups and women have higher levels of need for hip and knee replacement but receive relatively fewer joint replacements. ${ }^{4-6}$ Many individuals are living for prolonged periods with severe osteoarthritis.

High-quality primary care is of clear importance for such a prevalent condition that has both major personal and social impact. This has been recognised by the National Institute for Health and Clinical Excellence (NICE), which has recently published guidelines for the care and management of osteoarthritis in adults. ${ }^{7}$ However, there is little published information on the quality of primary care for osteoarthritis in the UK. US studies have found the quality of osteoarthritis primary care to be suboptimal, with achievement of quality measures ranging from $31 \%$ to $64 \% .^{8}$

This study assessed the overall quality of recorded osteoarthritis treatment in primary care in an English county. It also assessed whether the recorded

J Broadbent, MSc, PhD, MFPH, specialist trainee in public health; $S$ Maisey, $M S c$, research associate; $R$ Holland, BA, $P h D, F F P H$, reader in public health medicine; N Steel, PhD, MRCGP, FFPH, senior lecturer in primary care, School of Medicine, Health Policy and Practice, University of East Anglia, Norwich.

Address for correspondence

Dr Nicholas Steel, School of Medicine, Health Policy and Practice, University of East Anglia, Norwich, NR4 7TJ. Email:n.steel@uea.ac.uk

Submitted: 10 June 2008; Editor's response: 22 July 2008; final acceptance: 15 October 2008.

(c)British Journal of General Practice 2008; 58: 839-843.

DOI: 10.3399/bjgp08X376177 


\section{How this fits in}

Osteoarthritis is the most common cause of disability in the UK, but little is known about the quality of primary care for people with osteoarthritis. Quality indicators can be used to measure the extent to which primary care for osteoarthritis meets pre-determined standards. This study found shortfalls in the recorded quality of osteoarthritis primary care. Quality varied by patients' age and by the severity of osteoarthritis, but not by their postcode deprivation score.

achievement of quality indicators (QIs) was associated with particular patient characteristics linked to the epidemiology and natural history of osteoarthritis, or with practice characteristics.

\section{METHOD}

\section{Data collection}

Eighteen general practices in Norfolk were selected to give equal numbers in three groups stratified by national deprivation score. This was done to ensure a range similar to the England profile. Practice deprivation scores were calculated as weighted means, based on the 2004 Indices of Multiple Deprivation (IMD) deprivation scores of each

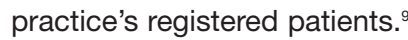

Between 20 and 40 randomly selected eligible patients at each practice were contacted for permission to examine their full patient records. Eligible patients were aged $\geq 55$ years, with diagnosed osteoarthritis or a symptom code for arthralgia (unless this was not due to osteoarthritis). They had consulted for osteoarthritis in the 12 months preceding data collection. The study was part of a wider analysis, ${ }^{10}$ and two rounds of data collection were undertaken, one in $2003(n=162)$ and one in $2005(n=158)$.

Data were extracted from electronic and paper records of 320 patients to assess recorded care against nine indicators. All aspects of the electronic medical records were included in the search for evidence of QIs, such as Read Code/BNF recording and free text. The entire paper record from date of diagnosis was also included. The data were extracted from patient records, with the researcher examining 305 records and an assistant examined 15 records.

\section{Derivation of quality indicators}

The included Qls were based on current evidence and were peer-reviewed by independent clinical panels, including UK GPs, in advance of the study. They originated from at least one of the following sources: NICE; ${ }^{11}$ RAND health indicators adapted by an independent expert panel including British GPs for the UK; ${ }^{12}$ and Quality Indicators for General

Table 1. Indicators of quality of osteoarthritis treatment in primary care.

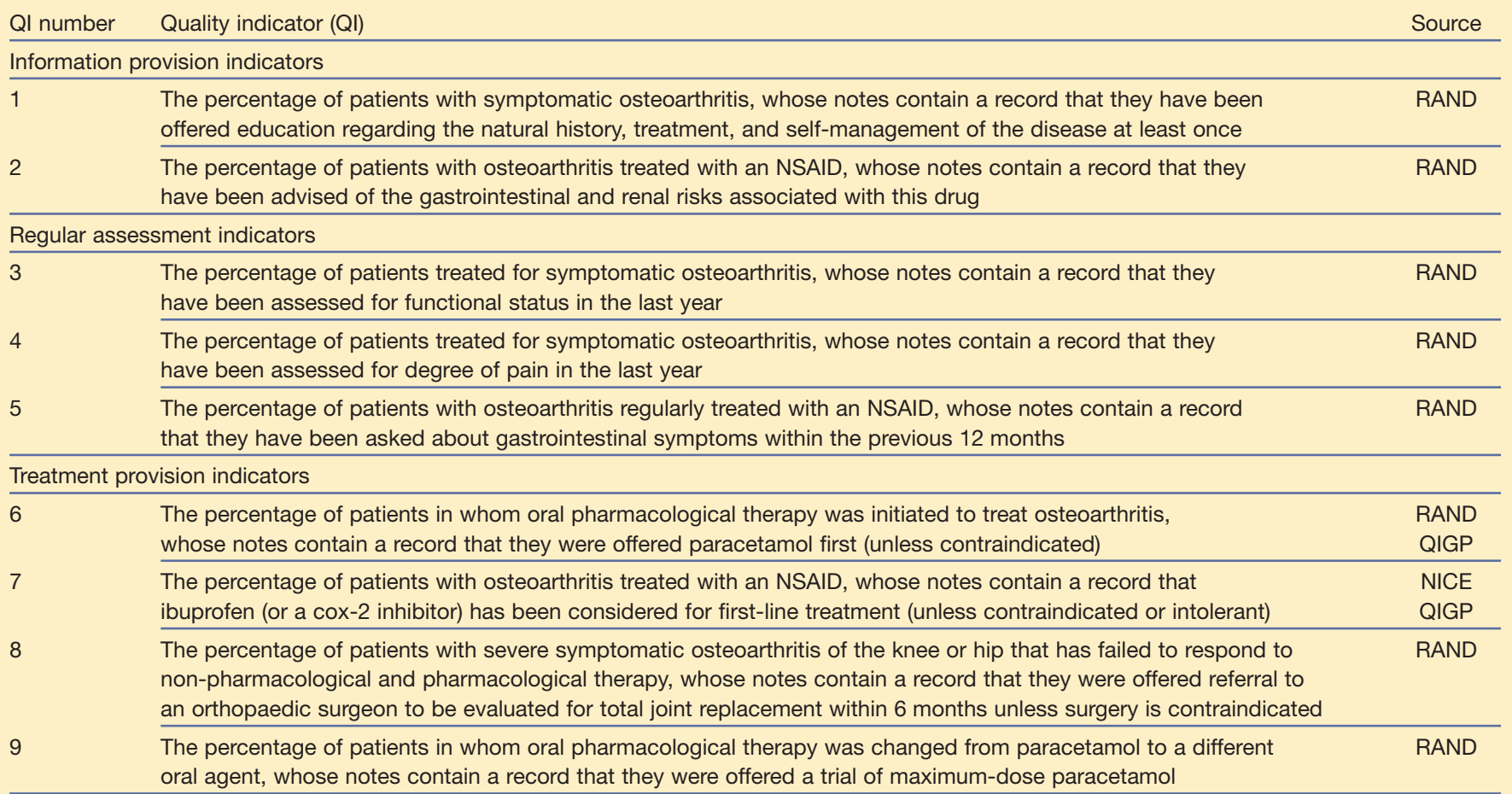

RAND $=$ RAND health indicators adapted for the UK. ${ }^{12}$ QIGP $=$ Quality Indicators for General Practice. ${ }^{13}$ NICE $=$ National Institute for Health and Clinical

Excellence. ${ }^{11}$ NSAID = non-steroidal anti-inflammatory drug. 
Practice (QIGP) developed at the National Primary Care Research and Development Centre. ${ }^{13}$ The included indicators covered the provision of information (QIs 1 and 2); regular assessment of pain, function, and side effects (QIs 3-5); and the provision of treatment (Qls 6-9; Table 1).

\section{Data analysis}

The number and proportion of eligible patients whose records indicated that each quality of care indicator was achieved was calculated. The proportion achieving indicators was analysed in relation to practice characteristics (practice level deprivation ${ }^{9}$ and size) and patient characteristics (age, sex, deprivation, severity of osteoarthritis, and time since diagnosis). Patient deprivation was calculated by using the National Statistics Postcode Directory $2007^{14}$ to find each patient's Lower Super Output Area (LSOA) of residence, and using the IMD $2007^{15}$ rank of this LSOA as an indicator of deprivation. All other information was obtained directly from patient records. Severe osteoarthritis was defined as 'symptomatic osteoarthritis of the knee or hip that has failed to respond to non-pharmacological and pharmacological therapy'. ${ }^{2,16,17}$ The same definition was used to assess eligibility for QI 8, resulting in colinearity of achievement of QI 8 with severe osteoarthritis. Multivariate logistic regression modelling of achievement of Qls was conducted including all patient and practice characteristics. Analyses were undertaken using Stata (version 9.1 StataCorp, College Station, TX, US).

\section{RESULTS}

\section{Participants}

A total of 320 patient records from 18 practices were examined. The patient response rate was $81 \%$ (320/393). Median age of participants was 71 years (range $55-95$ years), and 65\% $(n=209)$ of participants were female (Table 2). Non-responders were of similar age and sex to responders, with a median age of 70 years and $65 \%$ being female. Practice sizes and deprivation levels broadly reflected the range seen across England..$^{10}$

\section{Achievement of quality indicators}

Recorded achievement of individual Qls ranged from $5 \%$ (1\% to $14 \%$ ) for QI 9, to $90 \%$ (84\% to $95 \%$ ) for QI 8 (Table 3). QI 9 was achieved for only 3 of 61 eligible participants, and did not undergo logistic regression analysis due to the small numbers achieving the indicator. Recorded achievement ranged from $5 \%$ to $90 \%$ for indicators relating to the provision of treatment (QIs 6-9), from $17 \%$ to $30 \%$ for those relating to information provision (QIs 1 and 2 ), and $27 \%$ to $43 \%$ for those relating to regular assessment (Qls 3-5). Only QI 7 and QI 8 were achieved for over half of eligible participants.

\section{Effect of practice and patient characteristics}

Recorded achievement of Qls was not associated with either patient or practice-level deprivation, practice size, or time since diagnosis. Odds ratios for the explanatory variables that were statistically significantly associated with quality $(P<0.05)$ are shown in Table 3.

Recording of provision of education regarding the natural history, treatment, and self-management (QI 1) was less likely for older participants (OR 0.66, $95 \% \mathrm{Cl}=0.48$ to 0.90 ) compared with individuals 10 years younger; $P=0.004)$. Median age was 69 years where a record was found, compared with 72 years where it was not $(P=0.012)$. It was also more likely for women than men (OR 1.74, 95\% Cl = 1.01 to $3.00 ; P=0.047$ ).

A record of regular assessment (QIs 3 and 4) having been carried out was more likely for patients with more severe osteoarthritis (QI 3: OR 4.20, 95\% Cl $=2.58$ to $6.85 ; P<0.001$; and QI 4: OR $4.09,95 \% \mathrm{Cl}=$ 2.39 to $6.99 ; P<0.001)$.

Table 2. Distribution of practice and patient variables by participant.

\begin{tabular}{|c|c|c|c|}
\hline Practice variables & Description & $n$ & $\%$ \\
\hline \multirow[t]{4}{*}{ Practice deprivation } & Low (IMD 2004 rank 0-39.9\%) & 135 & 42.2 \\
\hline & Medium (IMD 2004 rank 40-64.9\%) & 92 & 28.8 \\
\hline & High (IMD 2004 rank 65-100\%) & 93 & 29.1 \\
\hline & Total & 320 & 100.0 \\
\hline \multirow[t]{4}{*}{ Practice size } & Small (501-5000 patients) & 49 & 15.3 \\
\hline & Medium (5001-10 000 patients) & 150 & 46.9 \\
\hline & Large (>10 000 patients) & 121 & 37.8 \\
\hline & Total & 320 & 100.0 \\
\hline \multicolumn{4}{|l|}{ Patient variables } \\
\hline \multirow[t]{3}{*}{ Sex } & Male & 111 & 34.7 \\
\hline & Female & 209 & 65.3 \\
\hline & Total & 320 & 100.0 \\
\hline \multirow[t]{3}{*}{ Severity of osteoarthritis } & Severe & 123 & 38.4 \\
\hline & Not severe & 194 & 60.6 \\
\hline & Total & 317 & 99.1 \\
\hline \multirow[t]{3}{*}{ Time since diagnosis } & $<2$ years & 98 & 30.6 \\
\hline & $\geq 2$ years & 220 & 68.8 \\
\hline & Total & 318 & 99.4 \\
\hline \multirow{3}{*}{$\begin{array}{c}\text { Patient LSOA } \\
\text { deprivation }\end{array}$} & High (IMD 2007 rank 106-18 562) & 162 & 50.6 \\
\hline & Low (IMD 2007 rank 18 721-31 754) & 151 & 47.2 \\
\hline & Total & 313 & 97.8 \\
\hline \multirow[t]{2}{*}{ Total } & & 320 & 100 \\
\hline & & Median & Range \\
\hline Age, years & & 70.5 & $55-95$ \\
\hline
\end{tabular}

Percentages do not always add up to 100.0 due to rounding. IMD = Indices of Multiple Deprivation. ${ }^{9}$ LSOA $=$ Lower Super Output Area. 
Table 3. Achievement of quality indicators (QIs) and related practice and patient characteristics.

\begin{tabular}{|c|c|c|c|c|c|c|c|}
\hline \multicolumn{4}{|c|}{ Achievement of Qls } & \multicolumn{4}{|c|}{ Multivariate analysis ${ }^{a, b, c}$} \\
\hline \multirow[b]{2}{*}{ QI } & \multirow{2}{*}{$\begin{array}{c}\text { Number of } \\
\text { patients eligible }\end{array}$} & \multicolumn{2}{|c|}{ QI met } & \multirow{2}{*}{$\begin{array}{l}\text { Statistically significant associated } \\
\text { characteristics }(P<0.05)\end{array}$} & \multirow[b]{2}{*}{ Odds ratio } & \multirow[b]{2}{*}{$95 \% \mathrm{Cl}$} & \multirow[b]{2}{*}{$P$-value } \\
\hline & & $n$ & $\%(95 \% \mathrm{Cl})$ & & & & \\
\hline 1 & 318 & 96 & 30 (25 to 36$)$ & Age versus 10 years younger & 0.66 & 0.48 to 0.90 & 0.004 \\
\hline & & & & Female & 1.74 & 1.01 to 3.00 & 0.047 \\
\hline 2 & 198 & 33 & 17 (12 to 23$)$ & None & & & \\
\hline \multicolumn{8}{|c|}{ Regular assessment indicators } \\
\hline 3 & 319 & 137 & 43 (38 to 49$)$ & Severe OA versus less severe & 4.20 & 2.58 to 6.85 & $<0.001$ \\
\hline 4 & 319 & 85 & 27 (22 to 32 ) & Severe OA versus less severe & 4.09 & 2.39 to 6.99 & $<0.001$ \\
\hline 5 & 113 & 34 & 30 (22 to 39$)$ & None & & & \\
\hline \multicolumn{8}{|c|}{ Treatment provision indicators } \\
\hline 6 & 268 & 129 & 48 (42 to 54$)$ & Age versus 10 years younger & 1.79 & 1.34 to 2.59 & $<0.001$ \\
\hline 8 & 123 & 111 & 90 (84 to 95$)$ & None & & & \\
\hline 9 & 61 & 3 & 5 (1 to 14$)$ & Insufficient data & & & \\
\hline
\end{tabular}

a Multivariate logistic regression. ${ }^{b} \mathrm{Q} / \mathrm{s}$ with incomplete records of explanatory variables excluded: three participants had incomplete severity information; two had incomplete length of diagnosis; eight had no Lower Super Output Area deprivation score. 'Age entered in regression analysis as continuous measure and then odds ratio converted from a difference of 1 to 10 years, thus the presented odds ratios represents a difference of 10 years at any point on the age scale. $O A=$ osteoarthritis.

Recorded achievement of two Qls (Qls 6 and 7) referring to pharmacological therapy was more likely for older participants (QI 6: OR 1.79, 95\% CI $=1.34$ to $2.59 ; P<0.001$ compared with individuals 10 years younger; and $\mathrm{QI} 7$ : OR $1.63,95 \% \mathrm{Cl}=1.10$ to $2.37 ; P=0.006$ compared with individuals 10 years younger). Where Qls 6 and 7 were achieved the median ages were 72 and 71 years respectively, compared with median ages of 67 and 66 years where they were not achieved $(P<0.001$ and $P=0.012$ ).

\section{DISCUSSION}

\section{Summary of findings}

This study used nine evidence-based indicators to measure the quality of recorded primary care for osteoarthritis. For several indicators there was no indication in the majority of records examined that the expected level of care had been delivered, although there was substantial variation between indicators. Records of high-quality care were found more frequently in the notes of those with more severe osteoarthritis and older participants, but varied little by other patient or practice-level characteristics. The effects of age and severity on recording may be explained by aspects of the condition and of the service, such as the agerelated nature of osteoarthritis and the likelihood of patients with a more severe condition consulting more often. The association with severity may also be indicative of the influence of case mix on the recorded quality of care.

\section{Strengths and limitations of the study}

This study used robust evidence-based, peerreviewed clinical indicators to assess the quality of recorded primary care for osteoarthritis. The indicators refer to the processes of health care rather than outcomes, and as such have fewer problems with case-mix bias, may be more sensitive measures of quality, and are more clearly linked to remedial action to improve quality further. The size and deprivation scores of the study general practices were similar to the English national profile of general practices, and so the study findings may be generalisable nationally.

Full paper and electronic medical records were searched, and credit was given for any mention of the care, even if not fully documented. For example, credit for advising patients on non-steroidal antiinflammatory drugs (NSAIDs) about gastrointestinal and renal risks was given for a record of 'UWG' ('usual warnings given') in the notes. Compilation of the dataset relied on information being recorded in patient records, and as such may not be a complete reflection of each patient's consultations. This study estimated recording of high-quality care as a proxy for quality of care itself. However, accurate recording of care is an essential component of effective multidisciplinary care for chronic conditions, and should correspond at least to minimum acceptable levels of care. Alternative methods of assessing quality of care might include analysis of videotaped consultations, but that would introduce different biases. The indicators included only encompass a 
small proportion of care for osteoarthritis, and it is important to note that Qls cannot capture the full spectrum of patient-centred care.

\section{Comparison with existing literature}

Despite the high population impact of osteoarthritis, the quality of primary care for osteoarthritis in the UK has not been investigated previously. A recent study considering quality of osteoarthritis primary care among patients aged $\geq 75$ years in the US ${ }^{8}$ concluded that the "quality of osteoarthritis care for older adults is suboptimal', which is consistent with the findings of this study. Compared with the US study, a higher proportion of eligible patients in this study was referred for surgical treatment (90.2\% versus $72.4 \%$ ). However, a much lower proportion of patients appeared to be offered education about the condition (30.2\% versus $68.7 \%$ ), advised of the side effects of NSAID treatment (16.7\% versus $41.5 \%$ ), or assessed annually for functional status and degree of pain (34.8\% versus $60.6 \%$ ). These differences may stem partly from the older age of study participants in the US study and partly from the fact that this study relied on the recording of care in patient records instead of patient interview as used in the US study.

It has previously been shown that individuals from poorer socioeconomic backgrounds receive relatively fewer hip and knee replacements. ${ }^{4-6}$ In contrast, this primary care-based study showed no variation in recorded offers of referral by deprivation status.

\section{Implications for clinical practice}

There are three main implications of this work. First, this study has demonstrated the feasibility of using existing robust QIs to measure the quality of primary care for osteoarthritis. Second, if the recorded quality found in this study reflects actual quality of care, there is substantial scope to improve the quality of osteoarthritis management in primary care in the UK for at least some of the aspects of care measured. Improvements in evidence-based care are likely to reduce the burden of disability caused by this condition. The lack of differences between practices suggests that a system-level intervention may be needed to improve care across the country. Interventions designed to improve achievement of these indicators should be piloted in a small number of practices with measurement of clinical outcomes. Third, the results showed an apparently equitable distribution of care with respect to deprivation, a notable achievement given the existing higher prevalence of osteoarthritis in those from deprived areas. As primary care practitioners start to deliver improved care for osteoarthritis, it will be a challenge to maintain the level of equity that this study has found.

\section{Funding body}

Nicholas Steel was funded by a Primary Care Researcher Development Award from the UK National Coordinating Centre for Research Capacity Development (RDA03/21). Norwich Primary Care Trust Research Office contributed to practice expenses for this project

\section{Ethical approval}

Ethical approval was obtained from Central Norfolk Research Ethics Committee and research governance approval from Norfolk PCT (05/Q0101/37)

\section{Competing interests}

The authors have stated that there are none

\section{Acknowledgements}

Assistance was gratefully received from the patients and staff at the 18 Norfolk GP practices included in the study, from Allan Clark and Sivatharan Vedavanam at UEA, and from Jonathan Cox and Emma Rayfield at Norfolk PCT.

\section{Discuss this article}

Contribute and read comments about this article on the Discussion Forum: http://www.rcgp.org.uk/bjgp-discuss

\section{REFERENCES}

1. Craig R, Mindell J (eds). Health survey for England 2005: the health of older people. London: The Stationery Office, 2007.

2. Bajekal M, Primatesta P, Prior G (eds). Health survey for England 2001: disability. London: The Stationery Office. 2003.

3. Dawson J, Linsell L, Zondervan K, et al. Epidemiology of hip and knee pain and its impact on overall health status in older adults. Rheumatology 2004; 43(4): 497-504.

4. Steel N, Melzer D, Gardener E, et al. Need for and receipt of hip and knee replacement: a national population survey. Rheumatology 2006; 45(11): 1437-1441.

5. Dixon T, Shaw M, Ebrahim S, et al. Trends in hip and knee replacement: socioeconomic inequalities and projections of need. Ann Rheum Dis 2004; 63: 825-830.

6. Chaturvedi N, Ben-Shlomo Y. From the surgery to the surgeon: does deprivation influence consultation and operation rates? Br J Gen Pract 1995; 45: 127-131.

7. National Institute for Health and Clinical Excellence. The care and management of osteoarthritis in adults. London: NICE, 2008. http://www.nice.org.uk/CG59 (accessed 29 Oct 2008).

8. Ganz DA, Chang JT, Roth CP, et al. Quality of osteoarthritis care for community-dwelling older adults. Arthritis Rheum 2006; 55(2): 241-247.

9. Noble M, Wright G, Dibben C, et al. The English indices of deprivation 2004. Wetherby: ODPM Publications, 2004.

10. Steel N, Maisey S, Clark A, et al. Quality of clinical primary care and targeted incentive payments: an observational study. Br J Gen Pract 2007; 57(539): 449-454.

11. National Institute for Clinical Excellence. Technology appraisal guidance No. 27: guidance on the use of cyclo-oxygenase (Cox) II selective inhibitors, celecoxib, rofecoxib, meloxicam and etodolac for osteoarthritis and rheumatoid arthritis. London: NICE, 2001. http://www.nice.org.uk/nicemedia/pdf/coxiifullguidance.pdf (accessed 29 Oct 2008).

12. Steel N, Melzer D, Shekelle PG, et al. Developing quality indicators for older adults: transfer from the USA to the UK is feasible. Qual Saf Health Care 2004; 13(4): 260-264.

13. Marshall M, Campbell S, Hacker J, et al. Quality indicators for general practice: a practical guide for health professionals and managers. London: Royal Society of Medicine Press, 2002.

14. Office for National Statistics Geography. National statistics postcode directory. London: ONS, 2007. http://www.statistics.gov.uk/geography/nspd.asp (accessed 5 Nov 2008).

15. Department for Communities and Local Government. The English indices of deprivation 2007. London: The Stationery Office, 2008.

16. Wenger NS, Shekelle PG, Davidoff F, et al. Quality indicators for assessing care of vulnerable elders. Ann Intern Med 2001; 135(Suppl): 641-758.

17. Maclean CH, Pencharz JN, Saag KG. Quality indicators for the care of osteoarthritis in vulnerable elders. J Am Geriatr Soc 2007; 55: S383-S391. 